\title{
A Medical Hypothesis: Excessive Adaptation Results in Relative Hypothermia and Lymphocytopenia, as Seen in Carnivorous Aquatic Mammals
}

\author{
Mayumi Watanabe ${ }^{*}$, Chikako Tomiyama², Toru Abo $^{3}$ \\ ${ }^{1}$ Department of Medical Informatics, Niigata University Medical and Dental Hospital, Niigata, Japan \\ ${ }^{2}$ Department of Medical Technology, Graduate School of Health Sciences, Niigata University, Niigata, Japan \\ ${ }^{3}$ Toru Abo Research Centre, Niigata, Japan \\ Email: *watanabem62@gmail.com
}

Received 26 February 2016; accepted 28 May 2016; published 31 May 2016

Copyright (C) 2016 by authors and Scientific Research Publishing Inc.

This work is licensed under the Creative Commons Attribution International License (CC BY). http://creativecommons.org/licenses/by/4.0/

(c) (i) Open Access

\begin{abstract}
Body temperature is an important clinical indicator of health and illness. Many studies of human body temperature have been conducted; however, there are no studies that compare the body temperatures of humans and other homeothermic animals. Twenty-six homeothermic animal species, including humans, were selected and characteristics of their internal environment were studied based on previous reports. The studied species were divided into two groups based on habitat (eight aquatic and eighteen terrestrial species) and three groups based on diet (carnivores, herbivores, and omnivores). Body temperatures, erythrocyte counts, and lymphocyte percentages were compared between species and between groups. Our results showed that carnivores had lower body temperatures and erythrocyte numbers than herbivores, and lower lymphocyte ratios than both herbivores and omnivores. Aquatic mammals that experienced a second adaptation event during their evolutionary process had lower body temperatures and lymphocyte ratios than terrestrial animals. These results suggest that excessive adaptation induced by stress or a change in environment may result in relative hypothermia and lymphocytopenia, features that aquatic mammals with stressful evolutionary backgrounds share with human cancer patients. However, our study is based on analysis of previous observations and reports, and further research (e.g., larger-scale studies) is needed to support this hypothesis.
\end{abstract}

\section{Keywords}

Body Temperature, Erythrocyte, Lymphocyte, Carnivore, Adaptation

\footnotetext{
${ }^{*}$ Corresponding author.
}

How to cite this paper: Watanabe, M., Tomiyama, C. and Abo, T. (2016) A Medical Hypothesis: Excessive Adaptation Results in Relative Hypothermia and Lymphocytopenia, as Seen in Carnivorous Aquatic Mammals. Health, 8, 764-771. 


\section{Introduction}

The Japanese Meteorological Agency has been observing the weather since 1876. Its 140 years of records show that the historical highest and the lowest temperatures in Tokyo are $39.5^{\circ} \mathrm{C}(2004 / 7 / 20)$ and $-9.2^{\circ} \mathrm{C}(1876 / 1 / 13)$, respectively; these data demonstrate that the external thermal environment varies widely, with a range of $48.7^{\circ} \mathrm{C}$ [1]. However, human body temperature is maintained within a narrow range $\left(35.7^{\circ} \mathrm{C}-37.3^{\circ} \mathrm{C}\right.$ in males and $33.2^{\circ} \mathrm{C}-38.1^{\circ} \mathrm{C}$ in females) because humans are homeothermic [2].

In homeotherms, body temperature is a clinically important indicator of health and illness. Because of this, researchers have investigated the normal ranges of oral, rectal, tympanic, and axillary body temperatures in healthy adult men and women [2]. Moreover, we previously report that decreases in body temperature are associated with acute stress [3] [4], and hypothermia has been found in cancer patients and in cancer model mice [5] [6]. Thus, many studies of human body temperature have been conducted; however, comparative studies with other homeothermic animals have not been reported.

We also suggest that an excessive stress may lead to a shift of glucose metabolism from glycolysis pathway to the mitochondria pathways [6]. It may be considered that a drastic change in lifestyle can induce. In this study, we also discuss an excessive adaptation, which is often caused by a change of internal environment (e.g. hypothermia or lymphocytopenia). In the evolutionary history of homeotherms, some of them have experienced such large changes in lifestyles including habitation and food. In this study, we compare the body temperatures, erythrocyte numbers, and lymphocyte ratios of 26 homeothermic animals, including humans.

\section{Methods}

\subsection{Methods Description}

Twenty-six species of homeothermic animals were selected as shown in Figure 1. These animals were grouped by habitat into aquatic $(n=8)$ and terrestrial $(n=18)$ animals, and by food into carnivorous, herbivorous, and

\begin{tabular}{|c|c|c|c|c|}
\hline & & carnivore & herbivore & omnivore \\
\hline 1 & dolphins & $\mathrm{O}$ & & \\
\hline 2 & whale & 0 & & \\
\hline 3 & sea lion & 0 & & \\
\hline 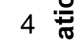 & elephant seals & 0 & & \\
\hline $5 \frac{0}{0}$ & walrus & 0 & & \\
\hline & habor seals & 0 & & \\
\hline 7 & polar bears & 0 & & \\
\hline 8 & sea otters & 0 & & \\
\hline 9 & cat & 0 & & \\
\hline 10 & rabbit & & 0 & \\
\hline 11 & cock & & 0 & \\
\hline 12 & pig & & 0 & \\
\hline 13 & goat & & 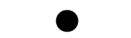 & \\
\hline 14 & sheep & & 0 & \\
\hline 15 & cow & & 0 & \\
\hline $16 \frac{1}{\sigma}$ & horse & & 0 & \\
\hline $17 \stackrel{0}{\frac{1}{2}}$ & deer & & 0 & \\
\hline $18 \stackrel{\text { d }}{5}$ & panda & & 0 & \\
\hline $19 \stackrel{ \pm}{ \pm}$ & mouse & & & $\bullet$ \\
\hline 20 & rat & & & 0 \\
\hline 21 & hamster & & & 0 \\
\hline 22 & marmot & & & 0 \\
\hline 23 & dog & & & 0 \\
\hline 24 & monkey & & & 0 \\
\hline 25 & human & & & 0 \\
\hline 26 & bat & & & 0 \\
\hline
\end{tabular}

Figure 1. Twenty-six species were investigated in this study. They comprised eight aquatic animals and 18 terrestrial animals. When grouped by diet there were eight carnivorous species, nine herbivorous species, and eight omnivorous species. 
omnivorous animals. Previously published values were used to compare body temperatures, erythrocyte numbers, and lymphocyte ratios between species [7]-[11], and mean values were compared between groups. The mean and S.D. were obtained from a numbers of animals $(n>10)$ except rare species of animals $(n=4$, whale and panda) with multiple samples in the range between 19 - 184 .

\subsection{Statistical Analysis}

The significance of between-group differences in mean values was assessed by the Mann-Whitney test or oneway analysis of variance followed by post hoc comparisons. The statistical software used was Statcel 2 (OMS Publishing, Saitama, Japan), which is written in Visual Basic for Applications, and IBM SPSS Statistics for Windows version 20.0 (IBM Corp., Armonk, NY). The level of significance was set at $p<0.05$ and all data are presented as means $\pm \mathrm{SD}$.

\section{Results}

\subsection{Comparisons between Species}

\subsubsection{Aquatic Animals, Pandas, and Humans Have Low Body Temperatures $\left(<37^{\circ} \mathrm{C}\right)$}

The body temperatures of the 26 studied animal species are diagrammatically shown in Figure 2. Seven species had body temperatures lower than $37^{\circ} \mathrm{C}$. These were five aquatic species (whale, walrus, dolphin, sealion, and polar bear), and only two terrestrial animals (humans and pandas). In contrast, eight species of land animals had body temperatures greater than $39^{\circ} \mathrm{C}$. The cock and the bat (during its active stage), both of which can fly, had the highest body temperatures of the studied animal species $\left(41.1^{\circ} \mathrm{C}\right.$ and $43.0^{\circ} \mathrm{C}$, respectively).

\subsubsection{Low Erythrocyte Numbers in the Cocks and Aquatic Animals.}

Figure 3 shows the erythrocyte numbers in the studied animals. Five species had less than $5.0\left(\times 10^{6} / \mu \mathrm{L}\right)$ erythrocytes. Four of these were aquatic species (elephant seal, walrus, dolphin, and harbor seal) and the rest was the cock. Three species of cloven-hoofed animals (deer, sheep, and goat) had more than $10.0\left(\times 10^{6} / \mu \mathrm{L}\right)$ erythrocytes. The goat had the highest erythrocyte count, with more than $18.0\left(\times 10^{6} / \mu \mathrm{L}\right)$ erythrocytes.

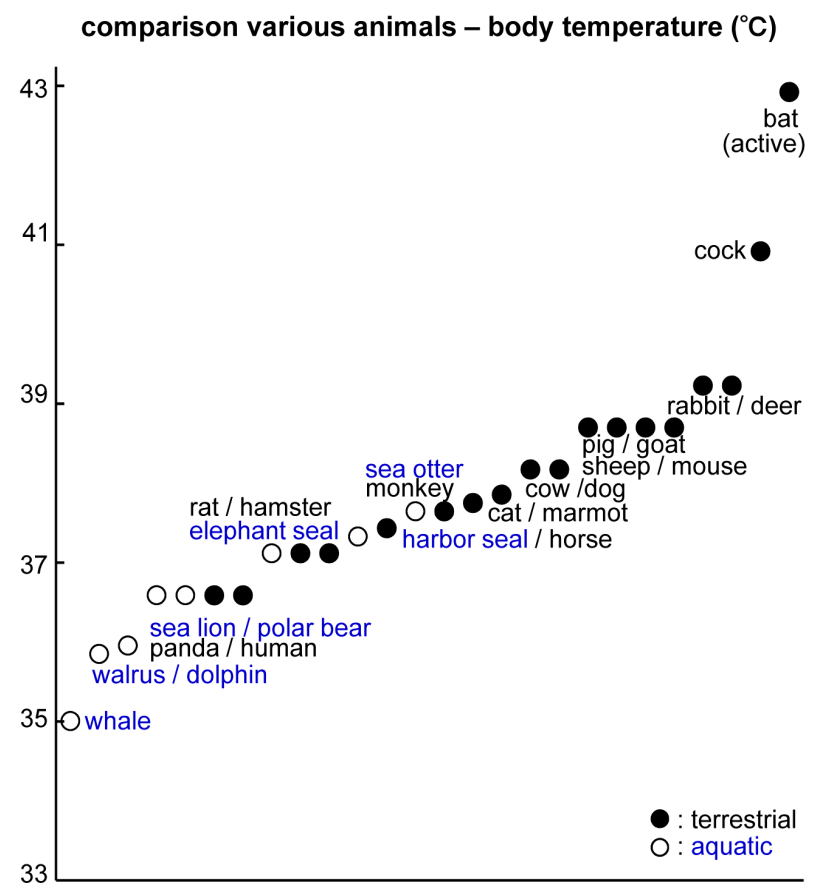

Figure 2. Comparison of the body temperatures of the studied species. Low body temperatures $\left(<37^{\circ} \mathrm{C}\right)$ were found in the aquatic animals, pandas, and humans. 


\subsubsection{Lymphocyte Percentages Distributed into Two Groups}

The lymphocyte percentages of the studied species are shown in Figure 4. The species could be categorized into two groups based on lymphocyte percentage: a lower group with less than 35\% lymphocytes and a higher group with more than $51 \%$ lymphocytes. There were 13 species in the lower group, including all eight of the aquatic species, as well as five of the terrestrial animals (pandas, horses, dogs, cats, and humans).

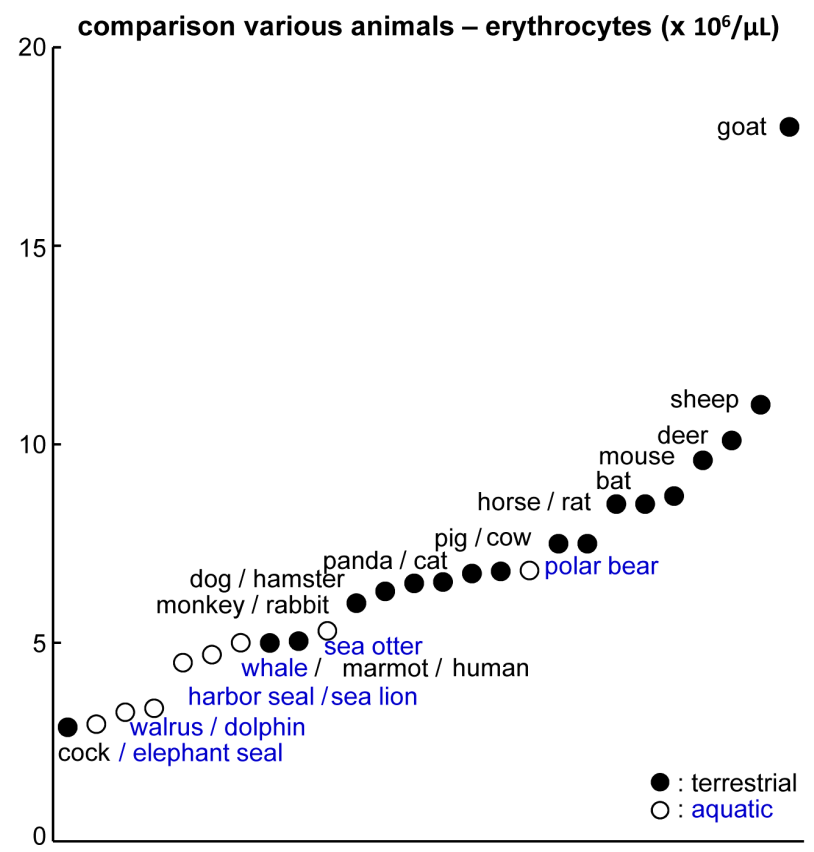

Figure 3. Comparison of the erythrocyte numbers in the studied species. The number of erythrocytes was high in the cock and low in the aquatic animals.

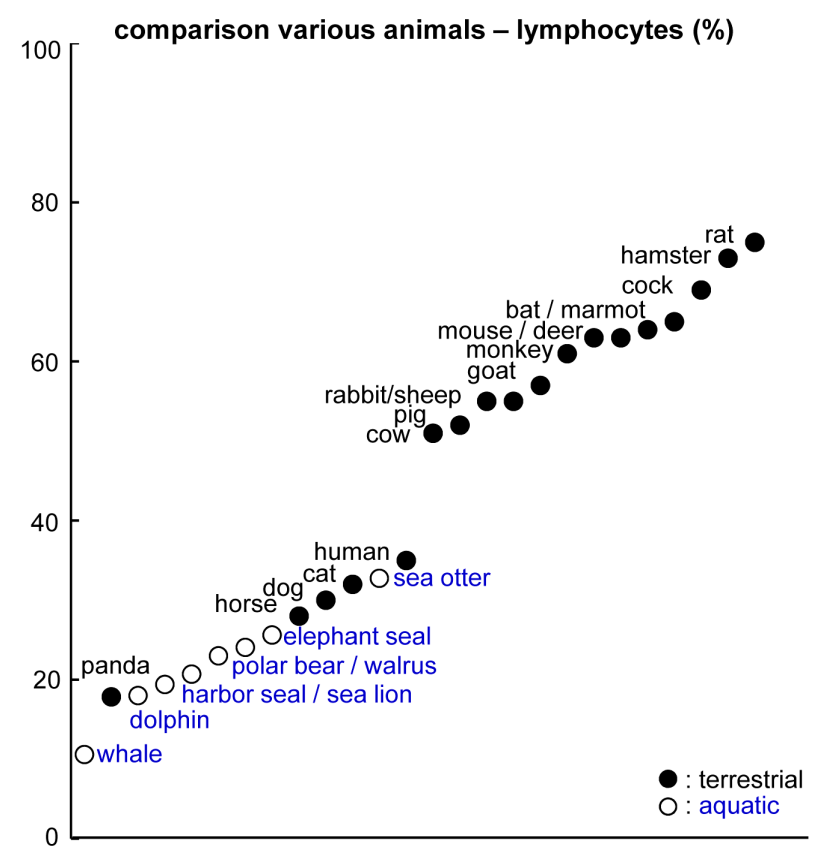

Figure 4. Comparison of the lymphocyte percentages of the studied species. The animals were distributed into two groups based on lymphocyte percentage. 


\subsection{Statistical Differences between Aquatic and Terrestrial Animals}

The significance of differences between the aquatic and terrestrial species studied was assessed using the MannWhitney test (Figure 5). Mean body temperature was significantly lower in the aquatic animals than in the terrestrial animals $\left(36.9^{\circ} \mathrm{C} \pm 0.8^{\circ} \mathrm{C} v s 38.5^{\circ} \mathrm{C} \pm 1.0^{\circ} \mathrm{C} ; p=0.002\right)$. The number of erythrocytes and the lymphocyte percentages were also lower in the aquatic species than in the terrestrial species (erythrocytes: $4.5 \pm 1.3$ vs $7.8 \pm$ $3.2\left(\times 10^{6} / \mu \mathrm{L}\right)$, respectively; $p=0.004$; lymphocytes: $21.7 \% \pm 6.4 \%$ vs $52.6 \% \pm 16.9 \%$, respectively; $\left.p<0.001\right)$ (Figure 6).

\subsection{Statistical Differences between Carnivorous, Herbivorous, and Omnivorous Animals}

The significance of differences between carnivorous, herbivorous, and omnivorous animals was assessed using one-way analysis of variance followed by post hoc comparisons. The carnivorous group had a significantly lowermean body temperature than the herbivorous group (carnivore, herbivore, and omnivore: $37.1^{\circ} \mathrm{C} \pm 0.9^{\circ} \mathrm{C}$, $38.9^{\circ} \mathrm{C} \pm 1.2^{\circ} \mathrm{C}$, and $38.0^{\circ} \mathrm{C} \pm 0.7^{\circ} \mathrm{C}$, respectively; $\left.p<0.01\right)$. Carnivores also had significantly fewer erythrocytes than herbivores (carnivore, herbivore, and omnivore: $4.7 \pm 1.4$, $8.7 \pm 4.2$, and $7.0 \pm 1.7\left(\times 10^{6} / \mu \mathrm{L}\right.$ ), respectively; $p<0.01$ ), and lower lymphocyte ratios than the animals in either of the other dietary groups (carnivore, herbivore, omnivore: $41.8 \% \pm 16.7 \%, 50.2 \% \pm 16.4 \%$ and, $77.1 \% \pm 6.9 \%$, respectively; $p<0.01$ ).

\section{Discussion}

Our results revealed differences in body temperatures, erythrocyte numbers, and lymphocyte percentages between animals with different diets and habitats. In short, features of the internal environment of an animal may be determined by successful adaptation to its external environment.

\subsection{Carnivores Have Relatively Lower Body Temperatures, Erythrocyte Numbers, and Lymphocyte Percentages}

Carnivores had lower body temperatures and erythrocyte numbers than herbivores, and lower lymphocyte ratios

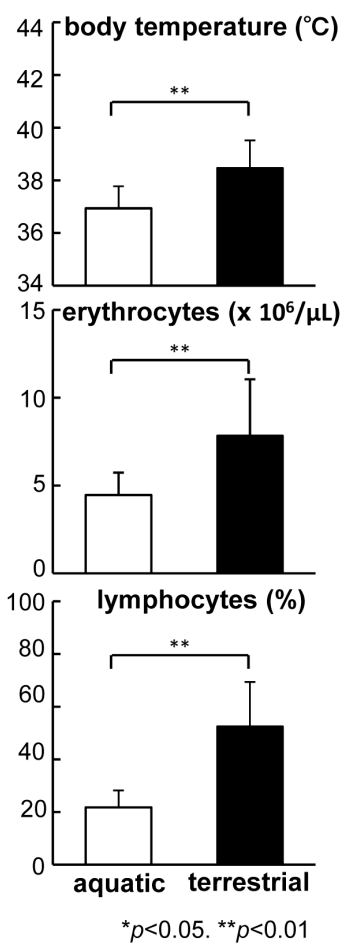

Figure 5. Differences between aquatic and terrestrial animals. There were statistically significant between-group differences in body temperature, erythrocyte number, and lymphocyte ratio. 


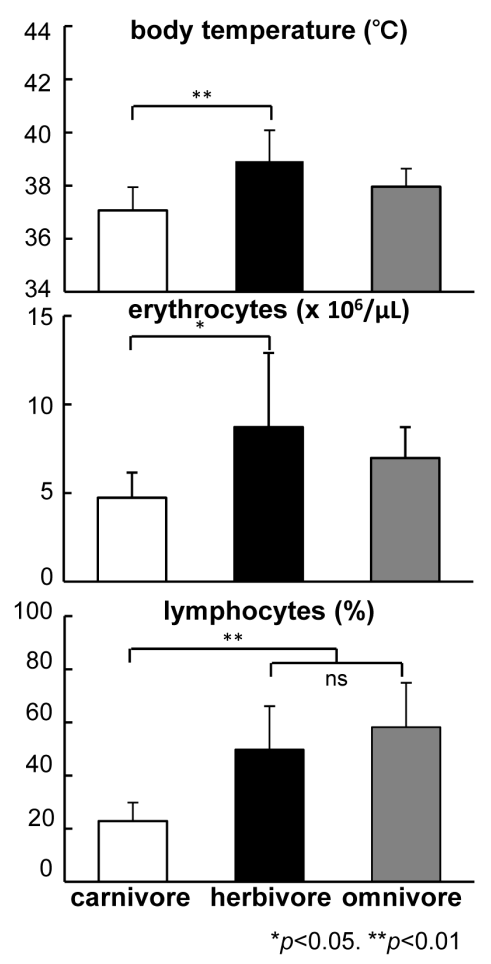

Figure 6. Differences between carnivores, herbivores, and the omnivores. Carnivorous animals had a lower mean body temperature and erythrocyte number than herbivores, and a lower lymphocyte ratio than both herbivores and omnivores.

than both herbivores and omnivores. Carnivorous animals are hunters that eat the meat of prey animals. Meat contains protein and fat, which are absorbed as amino acids and fatty acids and can be used to create energy. However, meat may also contain foreign antigens, such as bacteria, which may be one reason that the carnivores in this study had low lymphocyte ratios. Leukocytes can be broadly classified as either lymphocytes or granulocytes (with very few monocytes). Therefore, when the lymphocyte ratio is low, the granulocyte ratio is high. Granulocytes serve to protect against bacterial infection. Thus, a low lymphocyte/high granulocyte ratio would help carnivores defend against potentially pathogenic bacteria in their food.

To maintain a stable internal body temperature requires energy; however, carnivorous animals cannot always obtain meat. Therefore, they must avoid unnecessary energy expenditure. Their low body temperatures may be an energy conservation strategy because hypothermia decreases metabolic rate as well as their activity. Other energy-saving strategies include hibernation in winter and heterothermy, such as is utilized by bats. In many bat species, body temperature and metabolic rate are elevated only during activity. When at rest, these animals drastically reduce their metabolic rate and body temperature. They can switch their strategies between hyperthermia (fly) and hypothermia (rest).

In contrast, herbivorous animals have higher body temperatures than carnivores. Herbivores obtain energy from plant materials. However, their digestive organs, especially those of ruminants (such as cattle, goats, and sheep) are unable to produce the enzymes required to break down the plant cell walls (cellulose). Therefore, herbivores have developed a symbiotic relationship with microbes that digest the plant materials for them within a suitable temperature range. The heat generated by microbial fermentation within their gastrointestinal tracts might be one reason for the higher body temperatures of herbivorous animals.

\subsection{During Evolution Some Animals Emerged from, and Later Returned to, Water}

Fifty million years ago the ancestors of modern mammals emerged from the water and survived on land through adaptation to their new circumstance. However, 30 million years ago, some cloven-hoofed animals including the ancestors of modern whales, returned to the water to live as aquatic mammals. Thus, aquatic mammals had to 
adapt twice to a new external environment and can be said to have experienced a second adaptation event [12].

Our investigation revealed that homeothermic aquatic animals have lower body temperatures and lymphocyte ratios than homeothermic land animals. A recent study revealed that the panda also has a history of survival and a second adaptation event. In ancient days giant pandas were carnivorous; however, they began to eat bamboo, a food for which their alimentary tract is poorly adapted. The panda coped with this by achieving exceptionally low energy expenditure through reducing the sizes of several vital organs and through maintaining a very low physical activity level and body temperature [13]. Thus, animals with low body temperatures may have undergone greater adaptations, or more adaptation events, than those with higher body temperatures. Early human ancestors began bipedal walking 3.66 million years ago [14], likely because bipedal walking requires $75 \%$ less energy than quadrupedal walking [15]. Bipedal walking became the defining feature of the earliest hominids, and undoubtedly represented a drastic lifestyle change through adaptation; therefore, the low body temperature of humans might be due to our adaptation to bipedal locomotion.

Blood must be maintained at a physiologically appropriate viscosity while performing numerous functions. The high number of erythrocytes in the blood of herbivorous land animals allows rapid clot formation. This may be beneficial for terrestrial prey animals when they are attacked by a predator. By minimizing bleeding they maximize their chance of survival. Additionally, capillary blood flow can be regulated to prevent blood loss and to moderate mitochondrial glycolysis pathways for energy production [16]. A herbivore on land could escape from a predator using prompt energy production via glycolysis. However, due to its low body temperature, an aquatic animal would not benefit from a high number of erythrocytes as much as a land animal. At low temperatures blood becomes more viscous and clots more readily [17]; therefore, aquatic animals must have fewer erythrocytes than land animals to maintain proper circulatory function.

In this study, aquatic animals had lower lymphocyte ratios than terrestrial animals. This can be explained by the fact that all of the aquatic animals in this study were carnivores. Another possible explanation for this result may be found in their evolutionary process. Aquatic animals have a history of double adaptation-coming onto land 50 million years ago and then returning to the water 20 million years later.

\subsection{A Medical Hypothesis: Excessive Adaptation Results in Relative Hypothermia and Lymphocytopenia, as Seen in Carnivorous Aquatic Mammals}

Adaptive responses are often induced by stress and we have previously reported an adaptive glycolytic response to adverse internal conditions [5] [6]. In addition, we have shown that both hypothermia and lymphocytopenia are induced by stress [3] [4]. These findings suggest that carnivorous aquatic animals might have undergone huge stress during the evolutionary process.

This hypothesis may provide insights into our own health. Hypothermia and lymphocytopenia, which are features of aquatic mammals with stressful evolutionary histories, are also characteristics of the internal environment of cancer patients [5] [6]. In Japanese people, the average axillary body temperature had decreased from $36.8^{\circ} \mathrm{C}$ to $36.2^{\circ} \mathrm{C}-36.3^{\circ} \mathrm{C}$ during the last five decades in conjunction with an enormous change in lifestyle. At the same time, the number of cancer patients has significantly increased from 87,895 in 1958 to 368,103 in 2014 [18].

The results of our investigation suggest that a drastic change in lifestyle that induces excessive adaptation might be a cause of disease. However, our study had a major limitation in that we mainly analyzed previously reported observations; therefore, further research (e.g., larger-scale studies) is needed to support our hypothesis.

\section{Conclusion}

Carnivores had lower mean body temperatures and erythrocyte numbers than herbivores, and lower lymphocyte ratios than both herbivores and omnivores. Aquatic animals, which had experienced two adaptation events during evolution, had lower body temperatures and lymphocyte ratios than terrestrial animals. These findings suggested that excessive evolutionary adaptations to stress or a change in environment might result in low body temperatures and lymphocyte ratios, characteristics which were also typical of cancer patients

\section{Acknowledgements}

The authors thank Dr. Hajime Iwao, Niigata City Aquarium (Niigata, Japan) for valuable advice and helpful 
support.

\section{References}

[1] Japan Meteorological Agency, Ministry of Land, Infrastructure, Transport and Tourism of Japan. http://www.data.jma.go.jp/obd/stats/etrn/view/rank_s.php?prec_no=44\&block_no=47662

[2] Sund-Levander, M., Forsberg, C. and Wahren, L.K. (2002) Normal Oral, Rectal, Tympanic and Axillary Body Temperature in Adult Men and Women: A Systematic Literature Review. Scandinavian Journal of Caring Science, 16, 122-128. http://dx.doi.org/10.1046/j.1471-6712.2002.00069.x

[3] Kainuma, E., Watanabe, M., Tomiyama-Miyaji, C., Inoue, M., Kuwano, Y., Ren, H. and Abo, T. (2009) Association of Glucocorticoid with Stress-Induced Modulation of Body Temperature, Blood Glucose and Innate Immunity. Psychoneuroendocrinology, 34, 1459-1468. http://dx.doi.org/10.1016/j.psyneuen.2009.04.021

[4] Watanabe, M., Tomiyama-Miyaji, C., Kainuma, E., Inoue, M., Kuwano, Y., Ren, H., Shen, J. and Abo, T. (2008) Role of Alpha-Adrenergic Stimulus in Stress-Induced Modulation of Body Temperature, Blood Glucose and Innate Immunity. Immunology Letters, 115, 43-49. http://dx.doi.org/10.1016/j.imlet.2007.09.010

[5] Watanabe, M., Matsumoto, H., Tomiyama, C., Akazawa, K. and Abo, T. (2011) Internal Environment for Growth of Cancer Cells in Mice: Hypothermia, Anemia and Lymphocytopenia. Health, 3, 238-244. http://dx.doi.org/10.4236/health.2011.34042

[6] Watanabe, M., Miyajima, K., Matsui, I., Tomiyama-Miyaji, C., Kainuma, E., Inoue, M., Matsumoto, H., Kuwano, Y. and Abo, T. (2010) Internal Environment in Cancer Patients and Proposal That Carcinogenesis Is Adaptive Response of Glycolysis to Overcome Adverse Internal Conditions. Health, 2, 781-788. http://dx.doi.org/10.4236/health.2010.27118

[7] Kita, T. and Asakura, S. (1984) Zoo and Wild Animal Medicine. Buneido Shuppan Co., Ltd., Tokyo.

[8] Seki, M., Hirashima, K. and Kobayashi, K. (1981) Hematology of Experimental Animals. Soft Science Sha, Tokyo.

[9] Fowler, M.E. and Miller, R.E. (2003) Zoo and Wild Animal Medicine. 5th Edition, Saunders, St. Louis.

[10] Dierauf, L. and Gulland, M.D.F. (2001) CRC Handbook of Marine Mammal Medicine: Health, Disease, and Rehabilitation. 2nd Edition, Taylor \& Francis, UK. http://dx.doi.org/10.1201/9781420041637

[11] Hokuriku Regional Agricultural Administration Office (2008) Ministry of Agriculture, Forestry and Fisheries of Japan. http://www.maff.go.jp/hokuriku/kids/question/stock01.html

[12] Uhen, M.D. (2007) Evolution of Marine Mammals: Back to the Sea after 300 Million Years. The Anatomical Record, 290, 514-522. http://dx.doi.org/10.1002/ar.20545

[13] Nie, Y., Speakman, J.R., Wu, Q., Zhang, C., Hu, Y., Xia, M., Yan, L., Hambly, C., Wang, L., Wei, W., Zhang, J. and Wei, F. (2015) Animal Physiology. Exceptionally Low Daily Energy Expenditure in the Bamboo-Eating Giant Panda. Science, 349, 171-174. http://dx.doi.org/10.1126/science.aab2413

[14] Crompton, R.H., Pataky, T.C., Savage, R., D’Août, K., Bennett, M,R., Day, M.H., Bates, K., Morse, S. and Sellers, W.I. (2011) Human-Like External Function of the Foot, and Fully Upright Gait, Confirmed in the 3.66 Million Year Old Laetoli Hominin Footprints by Topographic Statistics, Experimental Footprint-Formation and Computer Simulation. Journal of the Royal Society Interface, 9, 707-719. http://dx.doi.org/10.1098/rsif.2011.0258

[15] Sockol, M.D., Raichlen, D.A. and Pontzer, H. (2007) Chimpanzee Locomotor Energetics and the Origin of Human Bipedalism. Proceedings of the National Academy of Sciences of the United States of America, 104, 12265-12269. http://dx.doi.org/10.1073/pnas.0703267104

[16] Abo, T., Watanabe, M., Tomiyama, C. and Kanda, Y. (2014) On/Off Switching of Capillary Vessel Flow Controls Mitochondrial and Glycolysis Pathways for Energy Production. Medical Hypotheses, 83, 99-100. http://dx.doi.org/10.1016/j.mehy.2014.03.035

[17] Rubenstein, E. and Lack, A. (1960) Extremity Venous Blood Temperature and Blood Clotting Mechanisms. Journal of Applied Physiology, 15, 598-602.

[18] Ministry of Health, Labour and Welfare of Japan (2015) Cancer Patient Information. Ministry of Health, Labour and Welfare in Japan. http://ganjoho.jp/reg stat/statistics/dl/index.html\#mortality 